\begin{tabular}{|l|l|}
\hline $\mathrm{CA}-4$ & 153 \\
\hline
\end{tabular}

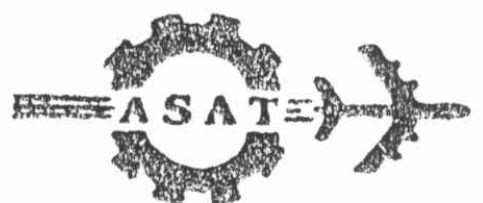

\title{
AIRCRAFT ACQUISITION AND OPERATION IN A TOTAL QUALITY ENVIRONMENT \\ Part II: Process Modeling and Improvement
}

\author{
By \\ Atef O. Sherif ${ }^{*}$ and Mohamed M. Elmaadawy **
}

\begin{abstract}
In part I of this work, a conceptual framework and approach for handling the problem of aircraft acquisition and operation in a total quality environment was presented. Decisions related to aircraft acquisition or operation are usually based on predicting the expected performance of Aircraft Mission Support Process (AMSP). The objective of part II is to present the modeling approach and improvement procedure of this process. The model is developed such that it can provide sampling experiments required for the application of Statistical Process Control (SPC) and process capability measures. A process capability index is used to measure the capability of the process in providing the system user with the required level of performance. Aircraft operational availability is taken as the process external performance indicator (or quality characteristic). A simple analytical model is investigated to determine its adequacy for the intended statistical analysis. Simulation is adopted as the preferred approach to model the process. Different acquisition options for improvement are evaluated by changing the design, support, and/or operational characteristics of the acquired system. For each option it is possible to determine the benefit and the worth of the change. Results of application of this approach show its power in predicting the process future performance. The suggested model could also provide an interfacing mechanism between aircraft users and suppliers in support of their mutual decision making during aircraft
acquisition or operation.
\end{abstract}

\section{INTRODUCTION}

In this part of the work, modeling and improvement of the Aircraft Mission Support Process (AMSP) will be performed by following the conceptual framework and approach that was presented in part I. This process incorporates the basic logical relationships, information flow, and material flow required for operating and maintaining an acquired aircraft during its operation phase. During acquisition, the characteristics of aircraft and its related operation and maintenance support requirements are determined. These characteristics establish a set of causes that affect the future (AMSP) performance during the operation phase.

During aircraft acquisition, tradeoffs between different polices (or options) are strongly required to insure that the user requirements are met by a preferred system configuration (or set of causes). For this purpose, (AMSP) is modeled such that the model output permits the application of Statistical Process Control (SPC) and process capability measures. This will provide a capacity to control and predict the future performance of this process which in turn will enhance the decision making capability of aircraft user and supplier.

\footnotetext{
${ }^{*}$ Professor, Aeronautics Dept., Cairo university.
} 
Using the internal and external performance indicators established in part I, the resulting Logistic Engineering Model, can be utilized in both the DO (D) and CHECK (C) phases of the so called "Shewhart's improvement cycle", fig.1. In these two phases the changes proposed in the PLAN (P) phase are set into motion on a trial basis, DO (D), and then evaluated, CHECK (C), before going to the ACTION (A) phase. This provides a mechanism for improvement until the user requirements are met. For demonstration, aircraft operational availability, as an external performance indicator, is considered in the improvement cycle.

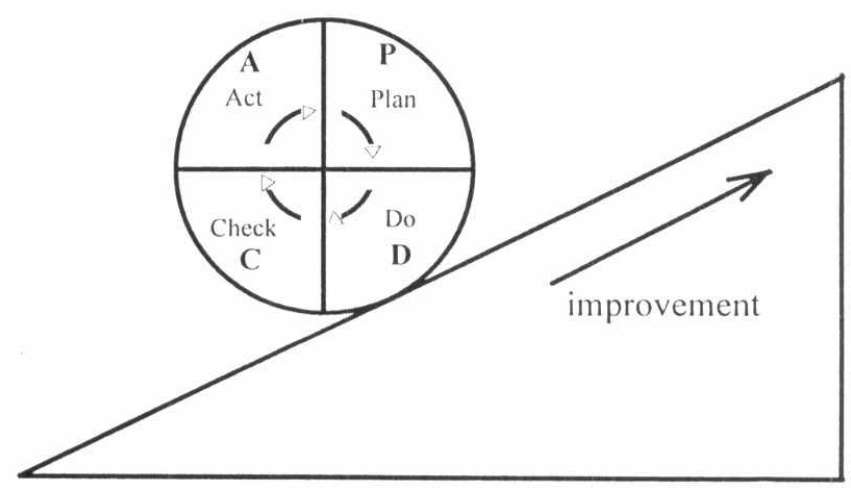

Fig.1. Shewhart's improvement cycle [Ref. 1]

\section{AIRCRAFT OPERATION AND MAINTENANCE}

Aircraft operation and maintenance are based on the three levels concept. They are the Organizational (O-level), Intermediate (I-level), and Depot (D-level). O\&I levels are the responsibility of the aircraft user while the D-level is the responsibility of aircraft supplier. At $\mathrm{O}$-level, on aircraft maintenance, mission activation and deactivation, and aircraft operation are carried out. Any maintenance tasks that are beyond the capability of O-level are transferred to I or D levels. Fig.2 shows a queuing network that represent a typical aircraft operation and maintenance support process. It is composed of eleven service stations. These stations make up three interacting queuing sub-systems. These sub-systems provide service for three different types of customers (transactions), missions, aircraft, and aircraft components. Each of these customers has its own attribute and acquire specific type of service. The queue discipline in the three sub-systems is First In First Out (FIFO). The subsystems are :

1- Mission Queuing Sub-System. It is composed of three series service stations, \#2, \#3, and \#4.

2- Aircraft Queuing Sub-System. It is a closed (or cyclic) queuing system. It is composed of eight service stations (\#1 through \#8).

3- Component Queuing Sub-System. It is a cyclic system composed of five service stations (\#7 through \#11). Each component has its own source of failure in the cycling aircraft.

Capacities of Aircraft Queuing Sub-System and Component Queuing Sub-System are limited by the number of the acquired aircraft and spare components respectively while the Mission Queuing Sub-System is open with unlimited capacity. 


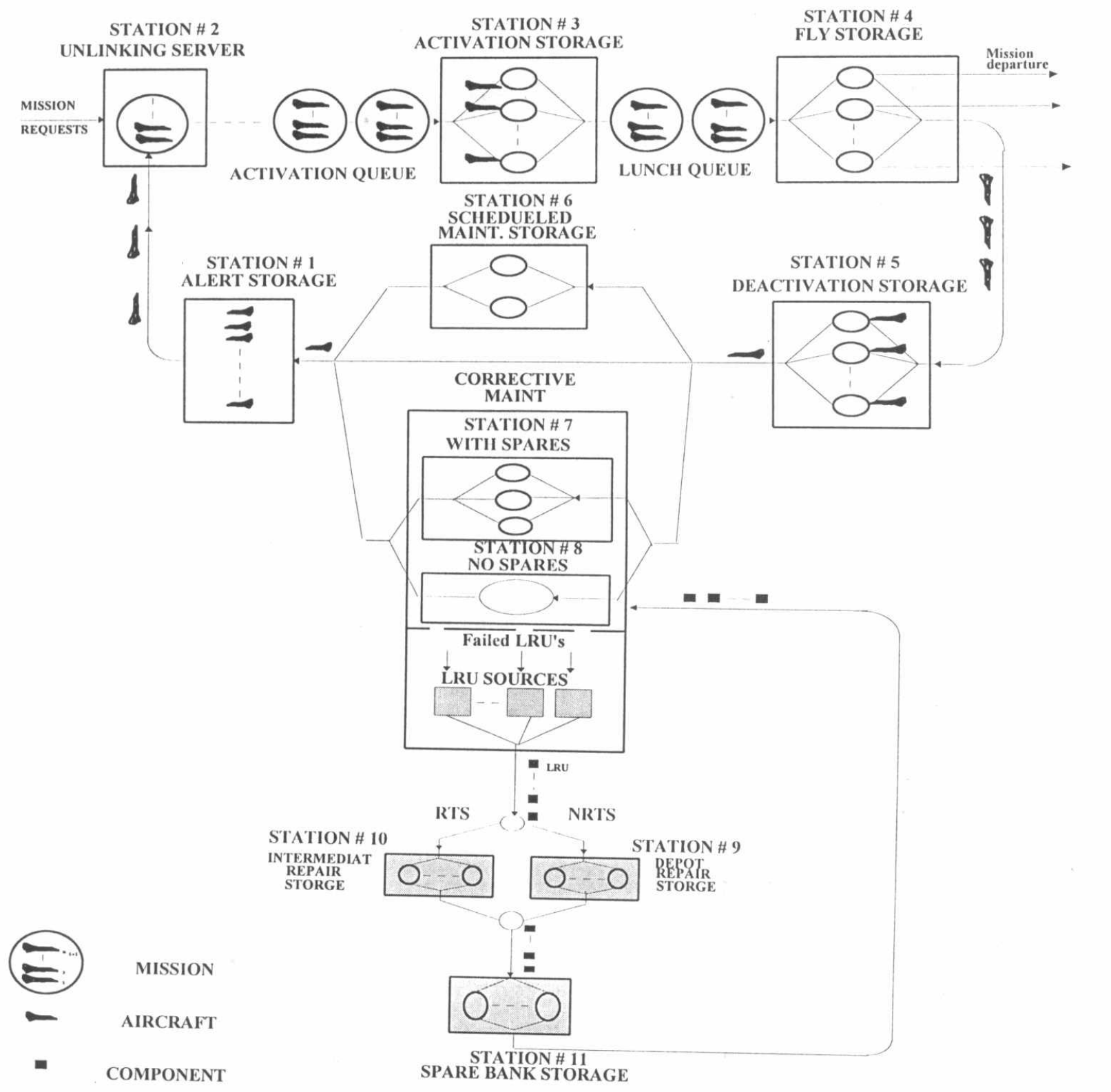

Fig.2. Aircraft Queuing Network

Aircraft operational availability $\left(\mathrm{A}_{\mathrm{O}}\right)$, as a quality characteristic, depends on the level of performance provided by the three queuing sub-systems. Generation of missions in the first sub-system will generate a demand on aircraft and aircraft components. This causes activation of the second and the third queuing sub-systems. Depending on the availability of serviceable components, an aircraft may be ready (available), down for maintenance, or down awaiting spares. Also, depending on the availability of ready (or serviceable) aircraft, mission accomplishment may be determined. $\left(\mathrm{A}_{\mathrm{O}}\right)$ is usually defined as the percentage of time in which an aircraft is in the up-state (uptime $=$ alert time + operation time).

$$
A_{\circ}=\frac{\text { Uptime }}{\text { Uptime }+ \text { Downtime }}
$$


or equivalently :

$$
A_{\circ}=\sum_{i=1}^{4} \overline{T i} / \sum_{i=1}^{8} \overline{T i}
$$

where $\overline{T i}$ is the average response time (waiting + service) of service station i in the Aircraft Queuing Sub-System (fig.2).

\section{PROCESS MODELING}

It is often turns out that it is difficult to develop analytical models for queuing systems. This may be due to the characteristics of the input or service mechanisms, the complexity of the system design, the nature of the queue discipline, or combination of the above. However both analytical and simulation modeling approaches are demonstrated.

\section{Analytical Modeling}

Developing an analytical model for the current queuing network, to calculate $\left(A_{O}\right)$ using equation 2 , is faced by the following considerations:

1- The Aircraft Queuing Sub-System is externally driven by the arrival of customers of the Mission Queuing Sub-System. Also, customers of Component Queuing Sub-System are activated and acquire service according to the state of customers in the other two queuing sub-systems.

2- Customers of the Component Queuing Sub-System are sometimes a subset of customers of the Aircraft Queuing Sub-System that are a subset of customers of the Mission Queuing Sub-System. This takes place when a component is installed on an aircraft and this aircraft is assigned to a mission.

3- A mission, as a transaction, may occupy more than one station at a time. This occurs when a mission is waiting at the launch queue while some of aircraft assigned to it are still in activation phase or even undergoing maintenance in the Aircraft Queuing SubSystem.

A simplified approach may be used to calculate $\left(\mathrm{A}_{\mathrm{O}}\right)$. It is based on the belief that, under a given steady state aircraft utilization, supply and repair of aircraft components has the major impact on $\left(\mathrm{A}_{\mathrm{O}}\right)$. This means that the effect of deactivation, scheduled maintenance, and corrective maintenance with spares available are negligible. In this case:

1- The Mission Queuing Sub-System is replaced by steady aircraft utilization.

2- $\quad$ The effect of Component Queuing Sub-System is replaced by a pipeline of aircraft component.

Fig.3 shows a simplified representation of the Aircraft Queuing Network. In this figure, aircraft operation availability $\left(\mathrm{A}_{\mathrm{O}}\right)$ is expressed as the probability of routing an aircraft directly to the alert storage (station \# 1) after mission completion. 


$$
A_{0}=\prod_{\ell=1}^{L}\left(1-\frac{(E B O)_{\ell}}{Q_{\ell}}\right)^{a_{\ell}}
$$

In equations 2 and $7,\left(\mathrm{~A}_{\mathrm{O}}\right)$ is calculated as a classical probability. This does not provide information concerning the variation in aircraft readiness from time to time. It does not describe the past, present, or future characteristics of the process. So, it does not support the application of Statistical Process Control (SPC) and process capability measures and provides unreliable means for prediction [1].

\section{Simulation Modeling}

To overcome the difficulties and constrains imposed by the analytical modeling, system simulation is adopted to model the (AMSP). Through simulation experiments, it will be possible to determine the process characteristics for selected time intervals and provide output that support the intended statistical methodology.

\section{Model structure}

The simulation model is developed using GPSS/PC software. It is built such that the model logic is consistent with the process of aircraft operation and maintenance support represented by the Aircraft Queuing Network, fig.2, and the elements of the (AMSP), fig.4. This figure shows the logical relationships, information flow, and material flow of (AMSP) elements.

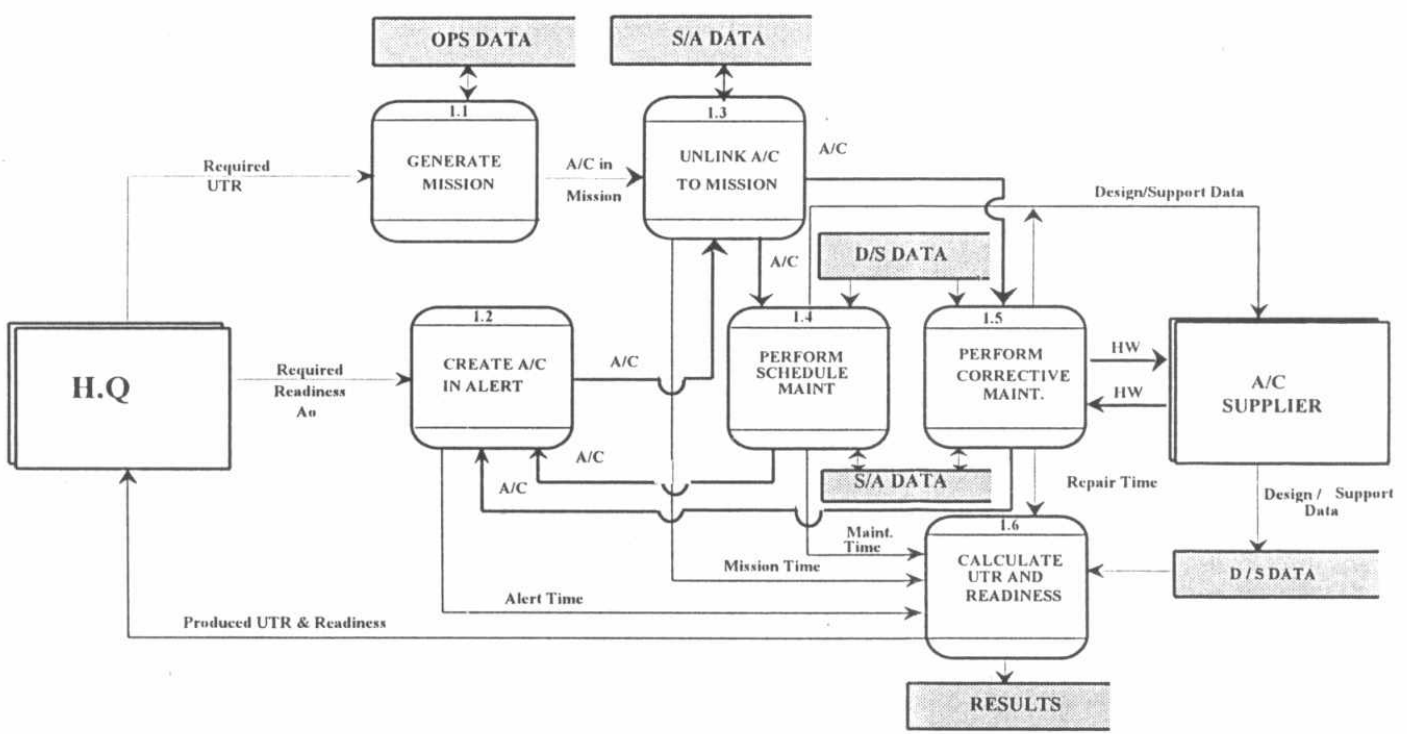

Fig.4. Elements Of Aircraft Mission Support Process [Ref. 3]

For each of the six sub-processes 1.1 through 1.6, a logic module is developed to simulate the underlying tasks and functions. For modeling purposes, process 1.5 is modeled by two logic modules. This gives the following seven logic modules that constitute the resulting Logistic Engineering Model:

1- Logic to create a master transaction to generate missions.

2- Logic for unlinking aircraft to go on mission. 


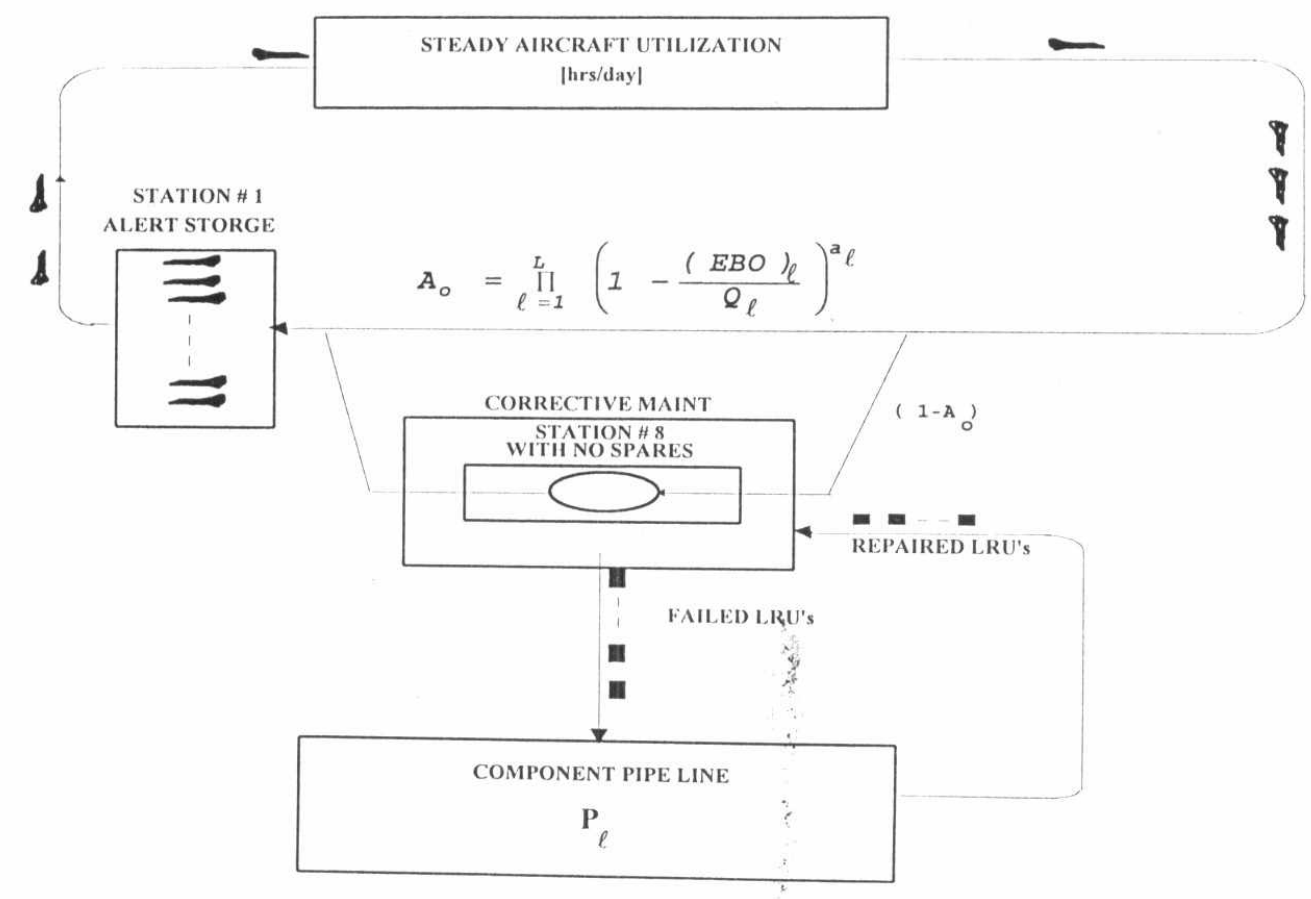

Fig.3. A Simplified Aircraft queuing Network

After a mission is completed, an aircraft will be routed to the alert storage if it is available, i.e. when it is not missing a component. In this case aircraft operational availability due to a
component $\ell$ will be :

$$
\left(A_{0}\right)_{\ell}=\left(1-\frac{(E B O)_{\ell}}{Q_{\ell}}\right)^{a_{\ell}}
$$

Where :

$\mathrm{a}_{\ell}$ is the quantity of component $\ell$ per aircraft,

$\mathrm{Q}_{\ell}$ is the total number of component $\ell$ in all aircraft, and(EBO) $\ell$ is the Expected Back Order of component $\ell$.

$$
\begin{aligned}
& (E B O)_{\ell}=\sum_{z>q_{\ell}}\left(z-q_{\ell}\right) P\left(z \mid p_{\ell}\right) \\
& p_{\ell}=d_{\ell} \cdot\left(\text { RTS. TTR } R_{I}+\text { NRTS. TTR } R_{D}\right)
\end{aligned}
$$

$P_{\ell}$ is the average repair pipe line quantity and $d_{\ell}$ is the daily demand rate.

$$
d_{\ell}=\frac{d_{a i l y} \text { Ilying hours }}{(M T B D)_{\ell}}
$$

RTS is the Repair This Station ratio = $(1-$ NRTS $)$. NRTS is the Not Repair This Station ratio. $\mathrm{TTR}_{\mathrm{I}}, \mathrm{TTR}_{\mathrm{D}}$ are Time To Repair at Intermediate and Depot maintenance in days respectively. $\mathrm{q}_{\ell}$ is the stock level of component $\ell$. MTBD is the Mean Time Between Demand. $\mathrm{P}\left(\mathrm{Z} \mid \mathrm{P}_{\ell}\right)$ is a Poisson distribution with mean $\mathrm{P}_{\ell}$ that represents the rate of arrival of aircraft components to the component repair pipe line. $Z$ is the variable stock level quantity [4]. For $\ell=1,2, \ldots, \mathrm{L}$, the overall operational availability will be:- 
Fig.6 shows the steady state process performance after the first three transient years of operation are omitted. Here, process capability index can be calculated and the future performance may be predicted.

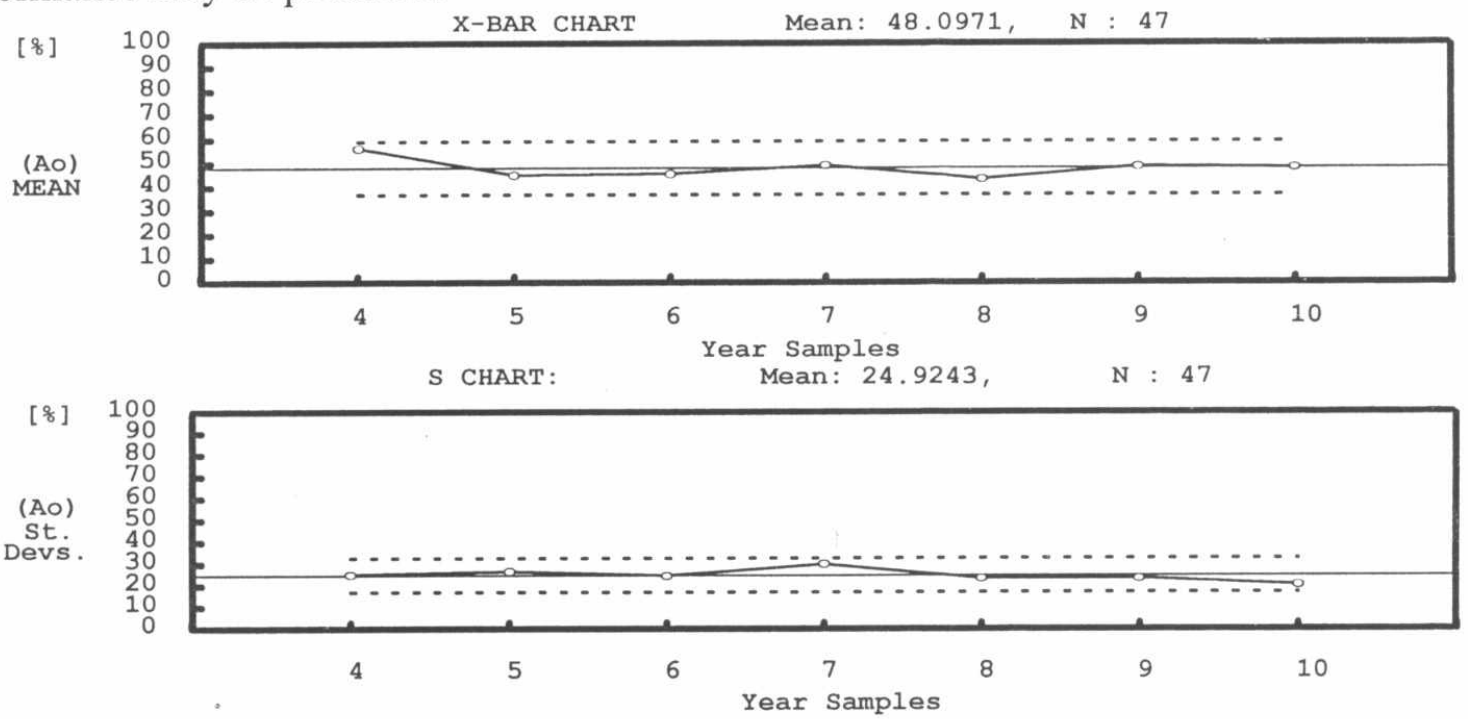

Fig.6. Ao Steady State X-BAR and S Charts.

The process will be capable only when the full distribution of $\left(A_{0}\right)$ always lies inside the two specified limits. Fig.7 shows a sample process output that is almost out of the specification limits given by the system user, $\left(70 \% \leq \mathrm{A}_{\mathrm{O}} \leq 100 \%\right)$. This means that the existing system of causes (NRTS, TTR $\mathrm{D}$, MTBD, UTR, and SPAR $\$$ ) is not able to meet the user requirements. So, a change in the set of causes that affect system readiness should be investigated.

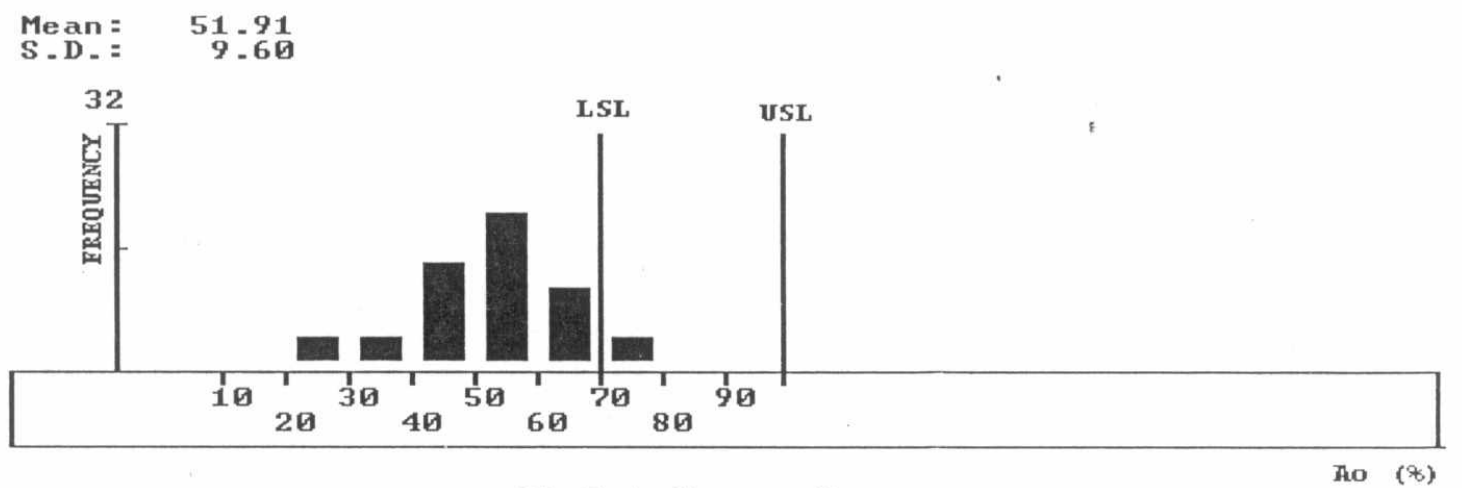

Fig.7. A Process Output

\section{PROCESS IMPROVEMENT}

It is frequently necessary to create external disturbances (special sources of variation) to a natural process to create improvements. The purpose of these external disturbances is to alter the basic structure of the process [1]. This concept will be applied by changing the elements of the set of causes. As an example, fig. 8 shows the effect of decreasing Time To Repair at the depot level $\left(T_{T R}\right)$ on $\left(A_{O}\right)$. 
3- Logic to create aircraft out in the alert area.

4- $\quad$ Logic to check the type of failure and do repair.

5- Logic to repair or replace failed components.

6- Logic to perform scheduled maintenance.

7- $\quad$ Logic to terminate the simulation and output results.

The data input to the model is selected such that all design, operational, support, and administrative factors (or causes) affecting $\left(A_{O}\right)$ are included. Operational, support, and administrative factors are always controllable. Design factors are controllable during aircraft design and development. However, design factors always contribute in the future readiness of the aircraft during the operation phase. Fig.4 shows, shaded blocks, where different types of data (or factors) fit in the logic of the (AMSP).

\section{Model application}

Using a given initial system configuration for acquiring a fleet of fighter aircraft, the model has been applied such that ten samples, for ten years of operation, of size $N=47$ (the total number of aircraft) are collected to perform the required statistical analysis. A length of 10 years of operation represents $50 \%$ of the system expected life. The initial system configuration assigns the following values for the five most likely factors (causes) affecting $\left(\mathrm{A}_{\mathrm{O}}\right)$ :

$$
\begin{array}{ll}
\text { NRTS }_{\text {max }} & =100 \% \\
\text { Mean TTRD } & =180 \text { with Standard Deviation }=20 \text { days } \\
\text { SPAR } \$ & =\$ 59.728 \text { million } \\
\text { MTBD }_{\min } & =22 \mathrm{hours} \\
\text { Required UTR } & =15 \mathrm{hr} / \mathrm{ac} / \mathrm{mo} .
\end{array}
$$

Fig.5 shows the X-BAR and $\mathrm{S}$ charts for the system operational availability for the first 10 years of operation. The X-BAR chart shows that there is a pattern of change (decrease) in level of performance from the first year to the fourth year. Starting from the fourth year, the process starts to level out and be under the state of statistical control.

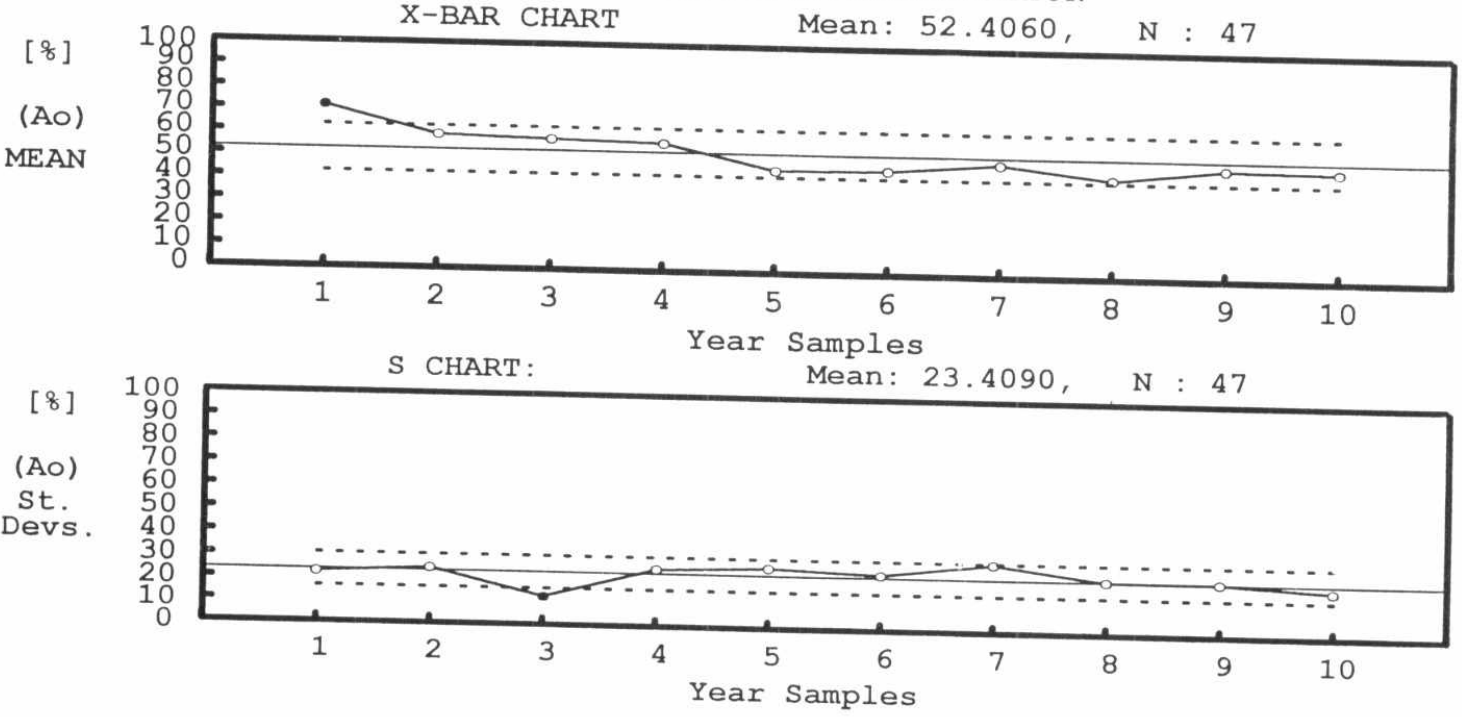

Fig.5. $A_{0} X-B A R$ and $S$ Charts 

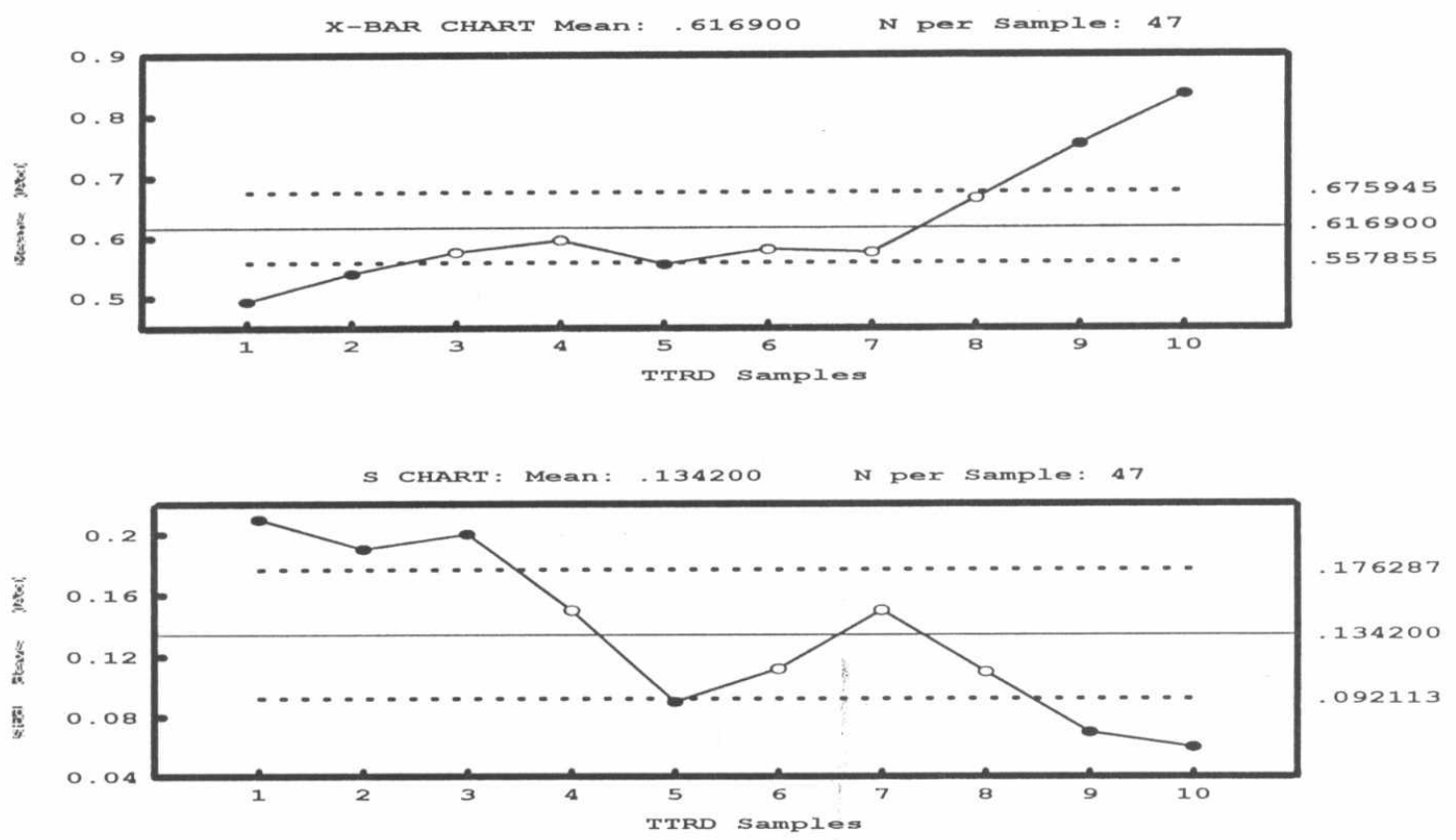

Fig.8. Effect of Decreasing $\mathrm{TTR}_{\mathrm{D}}$ on $\mathrm{A}_{0}$

Establishing of similar charts showed that a positive trend (i.e. improvement) of aircraft availability may be achieved by decreasing of $\mathrm{TTR}_{\mathrm{D}}$, decreasing of $\mathrm{NRTS}_{\text {max }}$, increasing SPAR\$, increasing $\mathrm{MTBD}_{\min }$ and/or decreasing the required UTR. This is supported by the resulted correlation between $\left(\mathrm{A}_{\mathrm{O}}\right)$ and these factors as shown in table 1 .

Table 1 Correlation with $A_{0}$

\begin{tabular}{|c|c|c|c|c|c|}
\hline Factor & NRTS $_{\max }$ & TTR $_{\mathbf{D}}$ & SPARS & MTBD $_{\min }$ & UTR \\
\hline $\mathrm{R}$ & -0.9160 & -0.8688 & 0.9177 & 0.9049 & -0.9402 \\
\hline
\end{tabular}

The five factors (variables) were introduced into a stepwise regression model. The order of their introduction was UTR, SPAR\$, TTR $\mathrm{D}, \mathrm{MTBD}_{\min }$, and then $\mathrm{NRTS}_{\max }$. The final determination factor (i.e. R-square) approaches the value 0.83 which means that $83 \%$ of the change (or variance) in $\left(A_{O}\right)$ is explained by the change in these five variables. Fig. 9 shows a pictorial representation of the contribution of each independent variable in estimating $\left(\mathrm{A}_{\mathrm{O}}\right)$.

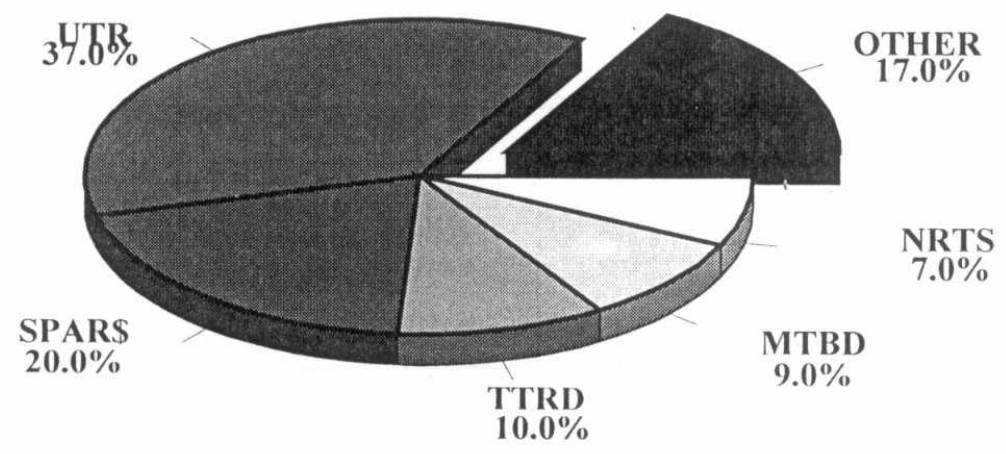

Fig.9. Contribution of $A_{0}$ Estimates 


\section{ESTABLISHING THE BENIFIT}

To establish the benefit (or the positive effect of improvement) is to analyze the worth of the change. The change is beneficial if it meets the user requirements without exceeding cost thresholds. Generally speaking, if the total benefit exceeds the cost, the change is valuable. Establishing the benefit is performed through the utilization of the process capability measure. For a two-sided specification limits, the process capability index Cpk is used to monitor the gain in process capability [2].

Table 2 shows the values of the five factors (variables)for three different acquisition options resulting from design and support changes. Required UTR is kept unchanged.

Table 2. Acquisition Options

\begin{tabular}{|c|c|c|c|c|c|}
\hline Option & NRTS $_{\text {max }}$ & $\begin{array}{c}\text { MTBD } \\
\text { (hr's) }\end{array}$ & $\begin{array}{c}\text { Mean TTRD } \\
\text { (days) }\end{array}$ & $\begin{array}{c}\text { SPARS } \\
\text { MS }\end{array}$ & $\begin{array}{c}\text { Input UTR } \\
\text { hr/ac/mo }\end{array}$ \\
\hline option \# 1 (initial system) & $100 \%$ & 22 & 180 & 59.728 & 15 \\
\hline option \# 2 & $50 \%$ & 400 & 120 & 59.728 & 15 \\
\hline option \# 3 & $50 \%$ & 400 & 120 & 66.844 & 15 \\
\hline
\end{tabular}

In options \# 2 and \# 3, decreasing of NRTS $\max$ is achieved by modifying test and support equipment while increasing of $\mathrm{MTBD}_{\min }$ is realized by reliability/maintainability improvement. Reduction of $\mathrm{TTR}_{\mathrm{D}}$ is obtained through a quality improvement effort for the depot repair cycle. Increase of SPAR $\$$ resulted from buying more spare components. Tradeoffs are required to decide the worth of these changes.

Fig.10 show the X-BAR and S charts with the transient period included (unstable process). $\mathrm{X}$-BAR CHART, $\mathrm{N}=47$

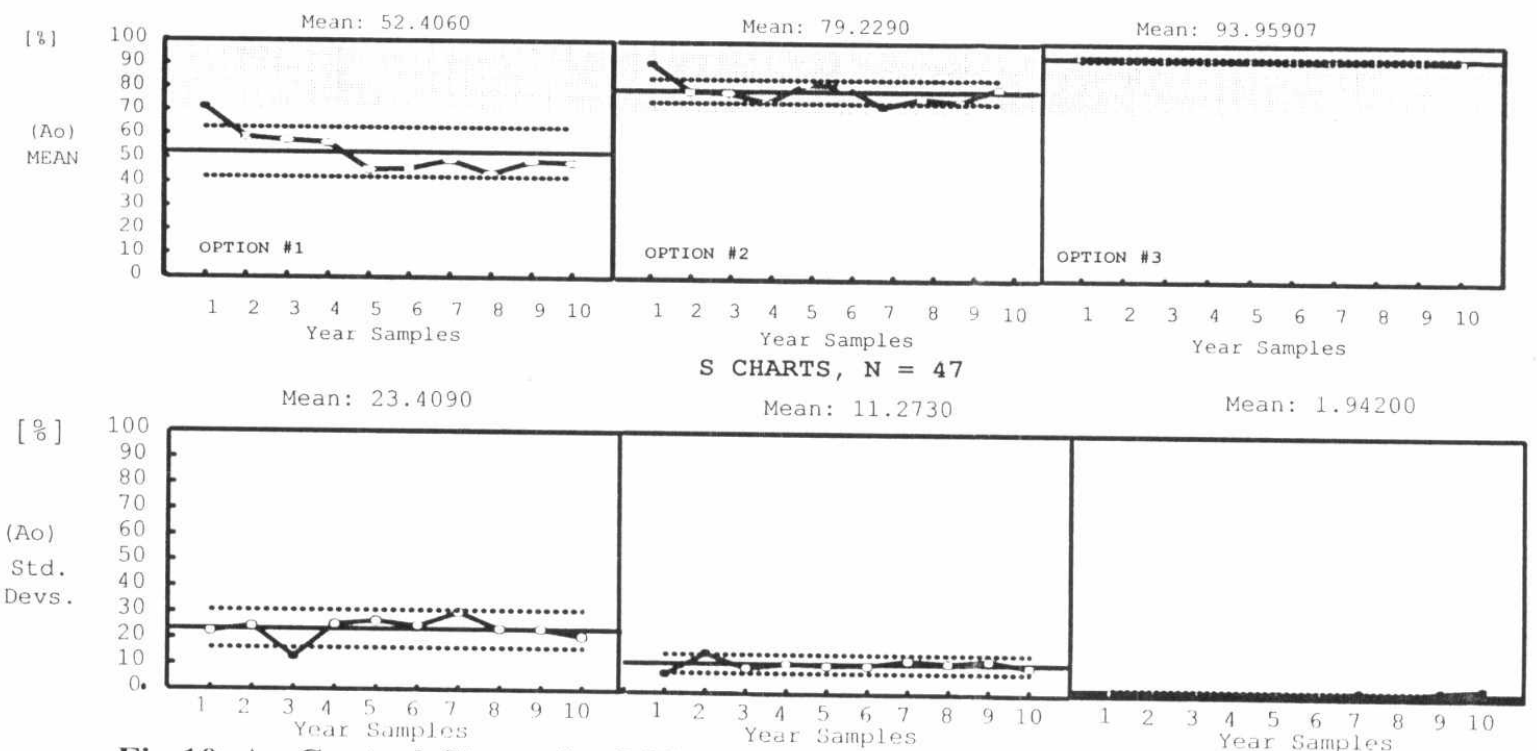

Fig.10. Ao Control Charts for Different Acquisition options (unstable process) 
Fig. 11 shows the X-BAR and S charts with the process stabilized and controlled. In option \#2, the mean of the process output (X-BAR chart) lies completely inside the specification limits given by the aircraft user. But, in the same time the user requirements are met $23 \%$ of the time $(\mathrm{Cpk}=0.23)$. So, the reliance on the mean value in prediction is completely misleading.

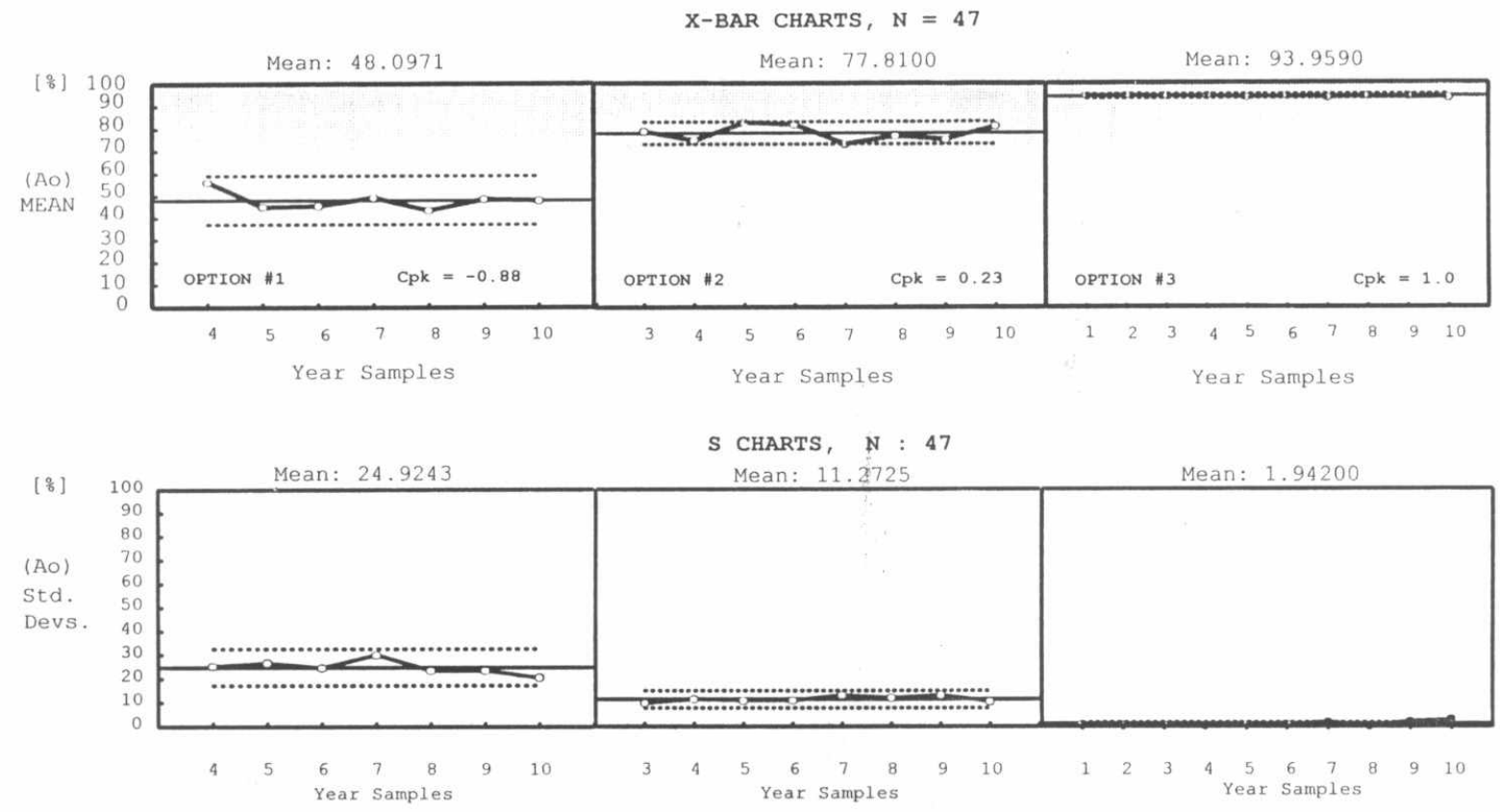

Fig.11. Ao Control Charts for Different Acquisition options (stable process)

Table 3 shows the improvement summary for the three acquisition options in which the marginal and cumulative benefit are illustrated. Option \#3 satisfies the user readiness and utilization requirements, reduces the waste, and diminishes the risk of acquisition $(\mathrm{Cpk}=1)$. In principle the total cost of improvement effort (e.g. R\&D, redesign, additional spares, ..., etc.) should not exceed the value of the cumulative benefit resulting from reduction in aircraft waste. Aircraft waste represents the cost of average unavailable (or down) portion of aircraft.

Table 3 Improvement Summary

\begin{tabular}{|c|c|c|c|c|c|c|}
\hline Cases & Cpk & $\begin{array}{c}\text { output UTR } \\
\text { hr/ac/MO }\end{array}$ & $\begin{array}{c}\mathbf{A}_{\mathrm{o}} \\
\text { Mean } \\
{[\%]}\end{array}$ & $\begin{array}{c}\text { Aircraft } \\
\text { WASTE } \\
\text { MS }\end{array}$ & $\begin{array}{c}\text { Marginal } \\
\text { Benefit MS }\end{array}$ & $\begin{array}{c}\text { Cumulative } \\
\text { Benefit } \\
\text { M\$ }\end{array}$ \\
\hline $\begin{array}{c}\text { Option \#1 } \\
\text { Initial System } \\
\text { Configuration }\end{array}$ & -0.88 & 11 & 48 & 488 & - & - \\
\hline Option \#2 & 0.23 & 15 & 77.8 & 208 & 280 & 280 \\
\hline Option \#3 & 1.0 & 15 & 93.95 & 56 & 152 & 432 \\
\hline
\end{tabular}

Fig.12 shows how an output distribution of $\left(\mathrm{A}_{\mathrm{O}}\right)$ approaches the user specification limits for the mentioned acquisition options. The same procedure can be applied for any other chosen quality characteristics. 


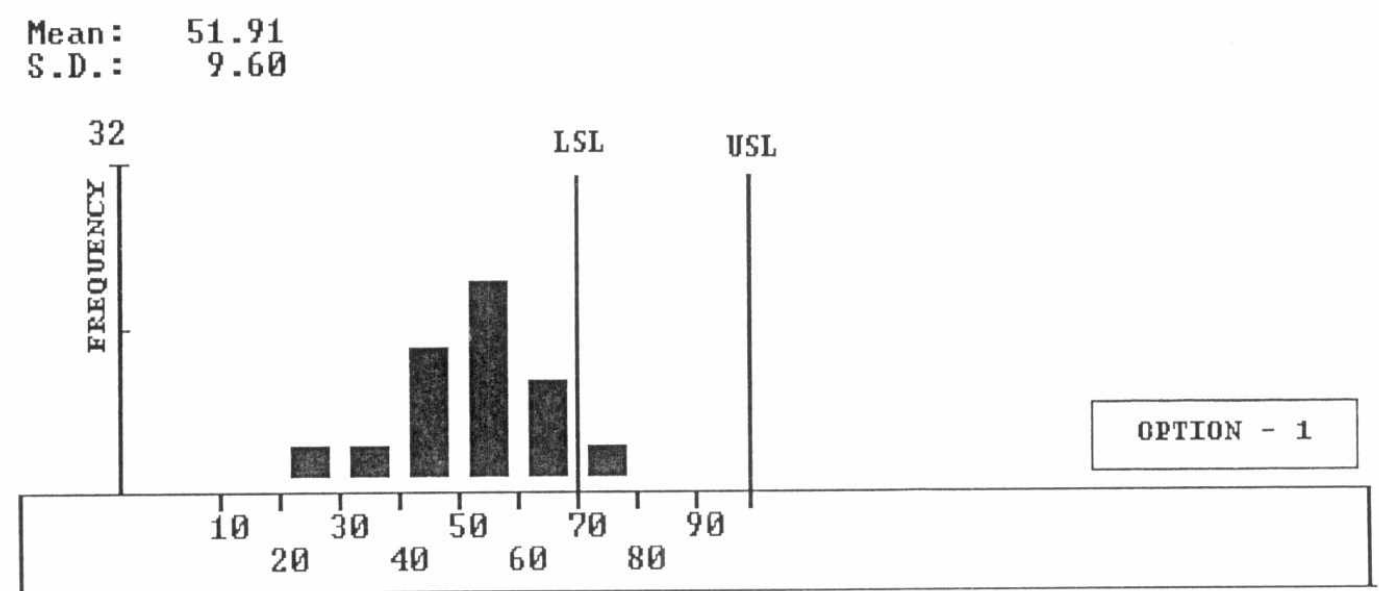

ค̆o (\$)

$\begin{array}{rr}\text { Mean: } & 78.66 \\ \text { S.D.: } & 9.57\end{array}$

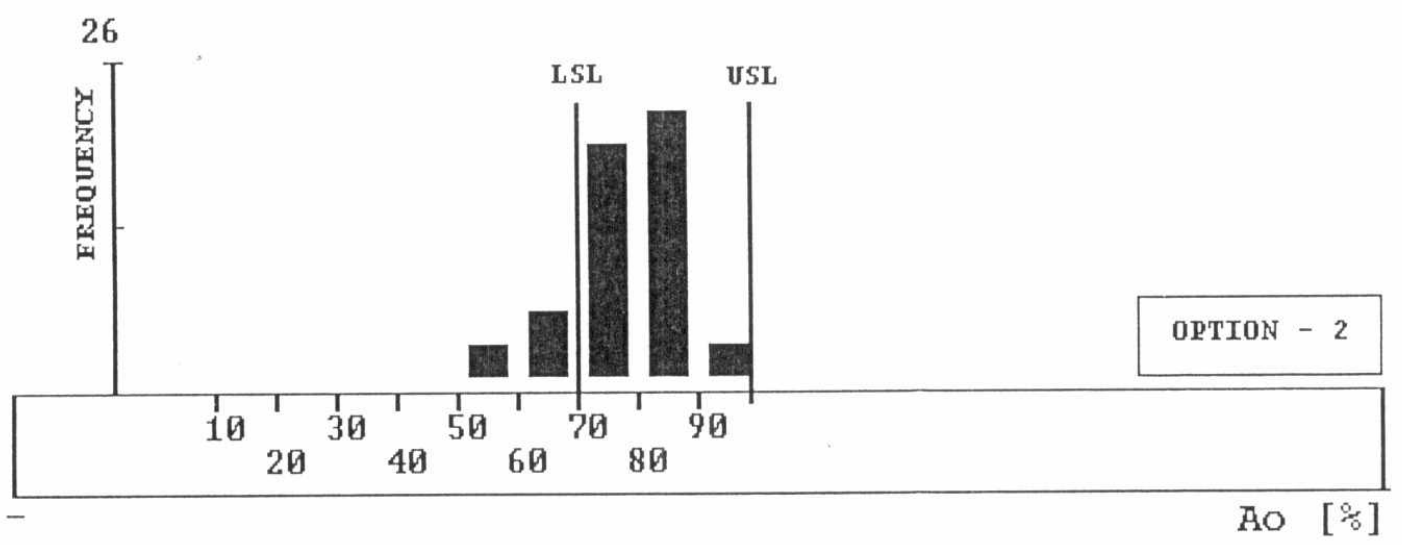

$\begin{array}{lr}\text { Mean: } & 94.21 \\ \text { S.D.: } & 1.46\end{array}$

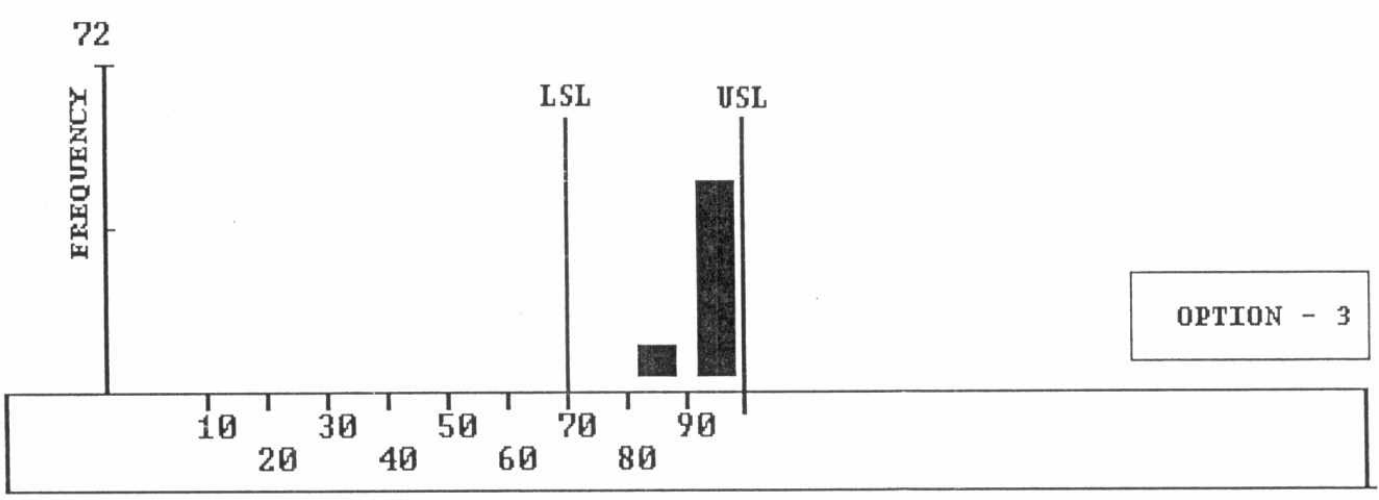

Fig.12. Ao for different acquisition options

AO $[\%]$

To insure the application of a total quality concept, improvement should take place internally on the sub-process level as well as externally on the process level. As an example, fig.13 shows the corresponding improvement in the aircraft Non-Mission Capable (NMC), as an internal performance indicator of sub process 1.5 of (AMSP), fig.4. 


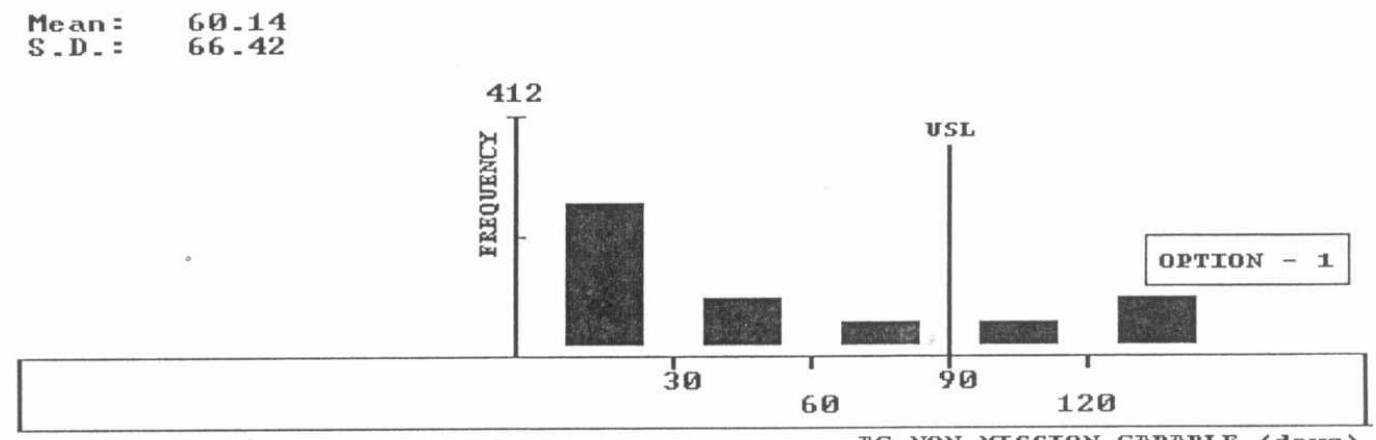

AC NON-MISSION CHPABLE (daYs)

$\begin{array}{ll}\text { Mean: } & 30.05 \\ \text { S.D.: } & 38.93\end{array}$

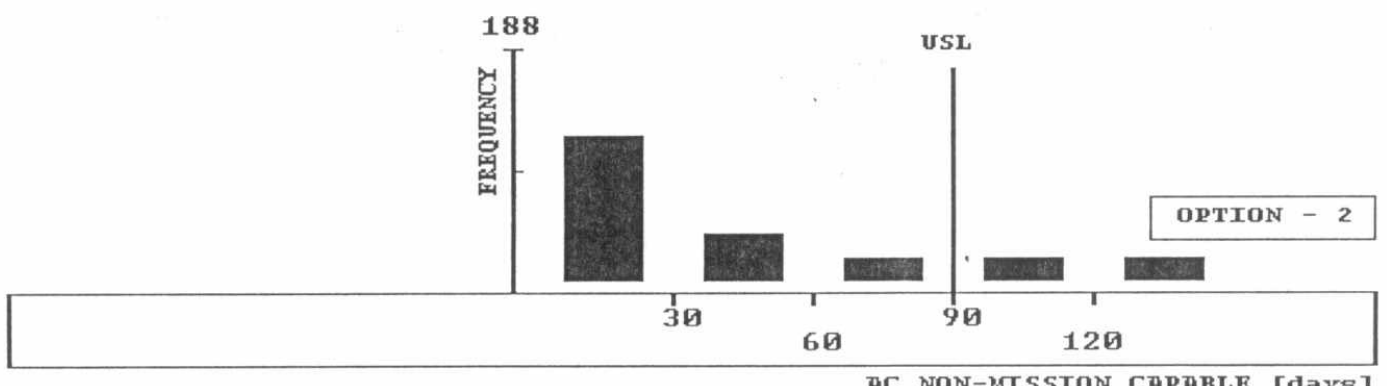

\begin{tabular}{lr} 
Mean: \\
S.D.: & $11: 74$ \\
\hline & 87
\end{tabular}

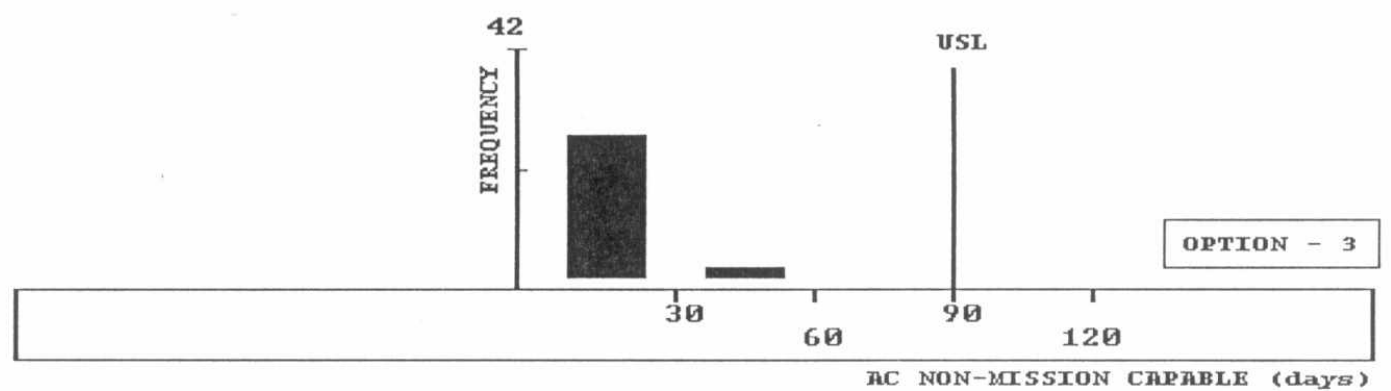

Fig.13. NMC for different acquisition options.

\section{THE IMPROVEMENT PROCEDURE}

The proposed improvement procedure for the Aircraft Mission Support Process is according to "Shewhart's improvement cycle":

1 Define the initial characteristics of the acquired system such that all design, support, and operational data input to the model are provided (PLAN).

2- Using the Logistic Engineering Model, a set of sampling experiments are performed to cover 10 years of aircraft operation (DO).

3- Construct $\mathrm{X}-\mathrm{BAR}$ and $\mathrm{S}$ charts for $\left(\mathrm{A}_{\mathrm{O}}\right)$. Then, stabilize and control the process by omitting the samples of the transient period. Then calculate the process capability index Cpk (CHECK).

4- If the process is incapable (i.e. Cpk < 1.0) make the necessary changes (design, support, operational) and repeat the improvement cycle (ACT) until Cpk $\geq 1$. 


\section{CONCLUSION}

Modeling and improvement of Aircraft Mission Support Process (AMSP) is performed based on the application of Total Quality concepts and tools. A simulation model is designed such that sampling experiments are made available for the application of Statistical Process Control (SPC) and process capability measures. This will provide a capacity for the aircraft user and supplier to control and predict (AMSP) future performance. The analytical modeling approach was found inadequate for the this purpose. To apply a total quality concept, internal and external performance indicators were established. For demonstration, aircraft operation availability is utilized as an external performance indicator during the improvement cycle. Through continuous reduction of variation and moving the process mean into the specification limits, it was possible to meet the user readiness and utilization requirements. Also, it was possible to determine the waste and risk for each improvement option. The risk of acquisition may be minimal when (ASMP) is capable (i.e. Cpk $\geq 1$ ). An application example on a real acquisition of a fleet of fighter aircraft demonstrated the power of this approach in performing design, support, and operational tradeoffs during aircraft acquisition and operation.

\section{REFERENCES}

[1] Howard Gitlow, etal. "Tools and Methods for Improvement of Quality".IRWIN,1989.

[2] Ronald J. Cottman "Total Engineering Quality Management" ASQC quality press, 1993.

[3] Mohamed. M. Elmaadawy and Atef. O. Sherif, "Aircraft Acquisition and Operation in a Total Quality Environment Part I: A conceptual framework and approach", sixth ASAT Conference, Cairo, 1995.

[4] T.J.O Malley. "The Aircraft Availability Model: Conceptual Framework and Mathematics". Logistics Engineering Management Institute, Washington,D.C.,1983.

\section{NOMENCLATURE}

$\begin{array}{ll}\text { A/c } & \text { Aircraft. } \\ \mathrm{A}_{\mathrm{O}} & \text { Aircraft operational availability. } \\ \mathrm{ABL} & \text { Allocated Base Line. } \\ \mathrm{AMSP} & \text { Aircraft Mission Support Process. } \\ \mathrm{Cpk} & \text { Process Capability Index. } \\ \mathrm{D} & \text { Depot. } \\ \mathrm{D} / \mathrm{S} & \text { Design/Support. } \\ \text { EBO } & \text { Expected Back Order. } \\ \text { FBL } & \text { Functional Base Line. } \\ \mathrm{HQ} & \text { Head Quarters. } \\ \mathrm{HW} & \text { Hardware (aircraft components). } \\ \mathrm{I} & \text { Intermediate. } \\ \text { LRU } & \text { Line Replaceable Unit, i.e. aircraft component. } \\ \text { LSL } & \text { Lower Specification Limit. } \\ \text { MTBD } & \text { Mean Time Between Demand. } \\ \text { N } & \text { Sample Size. } \\ \text { NMC } & \text { Non-Mission Capable. }\end{array}$


NRTS Not Repaired This Station Ratio.

O Organizational.

OPS Operations.

PAT Process Action Team

R Correlation Factor.

RTS Repair This Station.

S Sample Standard Deviation.

S/A Support/Administration.

SPAR\$ Spare cost

SPC Statistical Process Control.

SQD Squadron.

SRU Shop Replaceable Unit, i.e. aircraft sub-component.

TQE Total Quality Environment.

TTR $_{\mathrm{D}}$ Time To Repair at Depot level.

TTR I Time To Repair at Intermediate level.

USL Upper Specification Limit.

UTR Utilization Rate.

X-BAR Sample Mean. 